Studies in African Linguistics

Volume 27, Number 1, Spring 1998

\title{
A NOTE ON SUBJECT CLITICS IN AKAN*
}

\author{
Richard Campbell \\ Oakland University
}

This paper is concerned with the analysis of pronominal subject clitics (SCLs) in Akan within the Priniciples and Parameters framework of syntactic theory. Two kinds of analysis are considered: one, where the SCL is a true pronoun, generated in an argument position (the argument analysis); the other, where the SCL is an inflectional element residing in Infl, which identifies a null pronominal (pro) in subject position (the pro analysis). On the basis of the distribution of null objects in causative constructions, it is argued that the pro analysis provides a more elegant account of the facts of Akan than does the argument analysis. Akan is therefore analyzed as a pro-drop, or null subject, language, permitting null pronominal subjects under certain circumstances. Finally, possible implications for Universal Grammar are considered.

\section{Introduction: Two analyses of pronominal clitics}

Within generative syntactic theory, one issue in the analysis of pronominal clitics is this: is a pronominal clitic a true pronoun, that is, base-generated in an argument position like any other NP, and attached to its host by some syntactic or phonological process, or is the clitic base-generated in its surface position, and associated with an abstract (pronominal) argument? Kayne's [1975] analysis of object clitics in French is an example of the first type of analysis: object clitics are generated in post-verbal object position, and moved (by a rule of Clitic Placement) to their characteristic pre-verbal position; for Kayne [1975], then, (object) clitics are arguments. ${ }^{1}$

\footnotetext{
* I would like to thank Robert Botne and an anonymous reviewer for their helpful comments; all remaining errors are my own.

1 Kayne's [1972] analysis of subject clitics is a bit different, however: subject clitics in this analysis are base-generated together with an argument NP, and then adjoined to the verb. Thus,
} 
Jaeggli's [1981] analysis of subject and object clitics in French, and object clitics in Spanish and Italian, is an example of the second type of analysis: in Jaeggli's analysis, for example, French subject clitics are base-generated in Infl, 2 and associated with an abstract (that is, phonetically null) pronominal argument in subject position. For Jaeggli, then, clitic pronouns are not true pronouns at all, but a species of inflectional morpheme. In the second kind of analysis, French is actually a pro-drop, or null-subject language; the difference between French on the one hand and Spanish and Italian on the other hand, is that the condition under which the subject of a finite clause may be null (presence of a subject clitic for French; presence of "rich" agreement morphology in Spanish and Italian) is an optional feature of such clauses in French, but an obligatory feature in Spanish and Italian.

In this note I consider the analysis of subject clitics (henceforth SCLs) in Akan (Twi-Fante) within the Principles and Parameters framework (also called Government-Binding, or GB, Theory) [Chomsky 1981 and subsequent work]. The goals of the analysis are two-fold: on the descriptive level, to provide a language-internal argument for an analysis of Akan SCLs along the lines of the second type; that is, I will argue that SCLs are inflectional morphemes, not arguments, and that Akan allows null subjects when a SCL is present. The evidence for this conclusion comes from the behavior of object pronouns in causative constructions. On the theoretical level, I will consider some possible implications this conclusion has for the range of possible analyses of subject clitics countenanced by Universal Grammar (UG). Since the evidence for the analysis of SCLs as inflectional elements in Akan is rather abstract, it may not be available to the language learner, who must then fall back on principles of UG to determine the status of these elements. Therefore, the analysis of SCLs as inflectional elements may be dictated by UG.

\section{Akan Subject Clitics}

Examples of pronominal SCLs in Akan are given in (1). ${ }^{3}$

subject clitics for Kayne are not, strictly speaking, arguments, but are nevertheless base-generated within the subject position of the sentence.

2 This is something of an anachronism: Jaeggli proposes the following phrase structure rules (p. 92), where 'SCL' stands for subject clitic:
i. $\mathrm{S} \rightarrow \mathrm{NP}$ INFL' VP
ii. INFL' $\rightarrow$ (SCL) INFL

For present purposes, however, we can treat this as equivalent to generating the subject clitic within the inflectional head of the sentence, in more recent terms, in Infl.

3 Examples cited without a reference are from the Kwawu dialect, and are written in Akan orthography, which does not indicate tone or the effects of vowel harmony on prefixes; morpheme boundaries have been added. For typographical reasons, the letters ' $\varepsilon$ ' and ' $\rho$ ' will not be 
(1) a. Me=hye atadec.

I=wear cloth 'I am wearing clothes.'

b. Wo=ko Kumase dabiara.

you(SG)=go K everyday 'You go to Kumase every day.'

c. $0=r e-y \varepsilon \quad$ no.

$\mathrm{s} /$ he=PROG-insult her/him 'S/he is insulting him/her.'

d. $\varepsilon=y \varepsilon$ bia.

$\mathrm{it}^{4}=$ be beer

'It's beer.'

f. $Y \varepsilon=b \varepsilon-d a \quad h o$.

we=FUT-sleep there 'We will sleep there.'

g. $M o=a-b a$.

you(PL)=PERF-come 'You have come.'

h. Wo=wuuc.

they=died 'They died.'

That the SCL is phonologically dependent on the verb, and is not a free morpheme, is shown, for example, by the fact that the SCL shows the effects of vowel harmony with the verb and its other prefixes.

As stated in the introduction, two types of analysis of SCLs can be envisaged. According to the first type of analysis, illustrated in (2), Akan SCLs are underlyingly no different from English subject pronouns.

(2) SCL is an argument in SpecIP

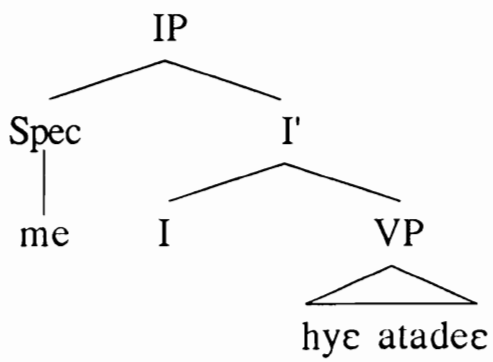

I will henceforth refer to this kind of analysis as the argument analysis of SCLs. I will not be concerned here with the issue of whether, in the argument analysis, the clitic pronoun is attached to Infl (or to V) by a syntactic movement operation, or by a purely phonological process of cliticization.

capitalized here. The following abbreviations are used in the glosses: FUTure, PROGressive, PERFect, NEGative, OPTative, LOCative, FOCus particle, $S G=$ singular, $\mathrm{PL}=$ plural.

4 Though I have glossed the SCL $\varepsilon=$ as 'it' in this example, inanimate pronominal forms are not specified for number. 
According to another analysis, on the other hand, the SCL is not an argument, but a functional element that serves to identify (in the sense of Rizzi [1986]) a null pronominal in subject position. According to this analysis, illustrated in (3), the SCL is generated in Infl, while the subject position is occupied by a null pronominal ('pro'). I will refer to this as the pro analysis. In the pro analysis, the SCL is essentially the spell-out of subject agreement (Agrs) features.

(3) SCL in Infl; SpecIP is pro

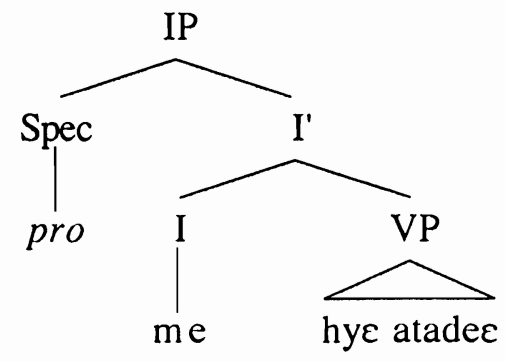

Regarding the pro analysis, note that a sentence need not have an SCL at all, if the subject is a lexical NP, as in (4). For the pro analysis to work, it must be the case that the SCL occurs in Infl only when pro is in SpecIP. 5 This is analogous to the behavior of pronominal SCLs in French, under this analysis.

(4) Kofi re-n-ko.

K. PROG/FUT-NEG-go 'Kofi won't go.'

I turn now to comparing the argument and pro analyses of SCLs in Akan. I will first consider null pronominals (pro) in object position (Section 3), and then causative constructions (Section 4). It will then be shown that object pro is impossible as the subject of a causative complement, even though other accusative pronouns are fine in that position (Section 5). I will then show that the argument analysis can account for this fact only with additional stipulations (Section 6), while the pro analysis provides a more elegant account (Section 7). A surprising result of the account in Section 7 is that, unlike SCLs in French, Akan SCLs might not be restricted to environments where nominative Case is assigned. Section 8 provides a discussion of the implications the analysis has for the nature of $U G$, and section 9 provides a conclusion.

5 Though a lexical NP subject cannot co-occur with a SCL in Kwawu, some other dialects of Akan permit it [Dolphyne 1988]. 


\section{Object Pro}

Akan, like many other West African languages, allows objects with inanimate reference not to appear (5). The verbs in (5) are not intransitive, but have null objects: In (5a), kyere 'catch' has the tone melody HL in Kwawu; the final $\mathrm{L}$ in the simple present form of verbs of this class, in which the root ends in [r] and the final vowel is a reduplicated version of the root vowel, indicates the presence of a direct object [Campbell 1988]. In (5b), di is obligatorily transitive; it is morphologically distinct from the intransitive didi 'eat', as in (6).

(5) a. Kofi kyérè _.

K. catch 'Kofi catches it.'

b. Kofi di _ nom nsuo.

K. eat drink water 'Kofi eats it and drinks water.'

(6) Kofi didie nomee.

K. ate drank 'Kofi ate and drank.'

Truly null objects, with inanimate pronominal reference, do, therefore, exist in Akan; I assume the null objects in (5) are pro. It must therefore be possible for [-animate] pro to be licensed independently of any (overt) functional element. Note that this conclusion is independent of the choice between the argument and pro analyses of SCLs. Either analysis, then, will have to assume that (7) is encoded in the grammar of Akan. 6

(7) In the absence of any other feature identification, pro is [-animate].

\section{Causatives}

In this section, I argue that the causative verb ma 'make' takes an IP complement, regardless of whether the subject of that complement is a lexical NP, accusative pronoun, or $\mathrm{SCL}$.

The causative construction in Akan involves a reduced clause complement to the causative verb ma, as in (8). The reduced clause complement in this construction is apparently IP. First, unlike full clausal complements, where an overt complementizer is usually required (9), no complementizer is possible in the causative construction (10). Since complementizers are normally required to be

6 This kind of general rule for identifying pro that is not identified by an overt element is proposed by Rizzi [1986] to account for arbitrary pro objects in Italian. However, the default identification for object pro in Italian is [+human, +arbitrary]. We are therefore forced to the conclusion that the features identified in such cases are not universal, but vary among languages. 
overt, its obligatory absence in (10) indicates the absence of Comp; hence, the complement is not $\mathrm{CP}$.

(8) Kofi maa [Amma dii bayere].

K. made A. ate yam

'Kofi made Amma eat yams.'

(9) Kofi kaa*(sc) o=do Amma.

K. said (that) $\mathrm{s} / \mathrm{he}=$ like $\mathrm{A}$.

'Kofi said that he likes Amma.'

(10) Yaw ma $\left({ }^{*} s \varepsilon\right)$ o $0=k o$ ho.

Y. make (that) $\mathrm{s} / \mathrm{he}=$ go there

'Yaw makes him/her go there.'

Second, the embedded clause can be independently negated (11), which indicates the presence of Infl [Campbell 1989, 1995].

(11) Kofi ma Yaw n-to nwoma no.

K. make Y. NEG-buy book that

'Kofi makes Yaw not buy the book.'

Third, the subject of the embedded clause ('causee') can be a SCL (12). Under both the argument and pro analyses SCLs are restricted to IP: in the argument analysis, because it is a nominative pronoun in SpecIP; in the pro analysis, because it is an inflectional morpheme in Infl.

(12) a. Kofi ma o=hu Yaw.

K. make $s /$ he $=$ see $Y$.

'Kofi makes her/him see Yaw.'

b. Kofi ma o=to nwoma no.

K. make s/he=buy book that

'Kofi makes her/him buy the book.'

An interesting feature of the causative construction is that a pronominal causee can be either one of two kinds: in addition to being an SCL, as in (12), the causee can also be an accusative pronoun, as in (13) (the third person singular accusative pronoun is no). There does not seem to be any appreciable difference in the interpretation of (12) and (13). The question we must address, then, is whether or not (12) and (13) have different structures, and what the structure of each is. 
a. Kofi ma no hu Yaw.

K. make him/her see Y.

'Kofi makes her/him see Yaw.'

b. Kofi ma no to nwoma no.

K. make him/her buy book that

'Kofi makes her/him buy the book.'

In the remainder of this section, I will argue that (12) and (13) have essentially the same structure; that is, that in both constructions ma 'make' takes an IP complement, with the causee in SpecIP. First, there is evidence that in both (12) and (13) the causee is the subject of the embedded clause, and not a subcategorized argument of the matrix verb. That is, there is reason to believe that (13) has the structure in (14a) (comparable to that in (8) above), and not the structure in (14b). If (13) had the structure in (14b), no would be the subcategorized object of ma, and would control PRO in the subject position of the complement clause.

(14) a. Kofi ma [no hu Yaw].

b. Kofi ma no [PRO hu Yaw]

Evidence against (14b) comes from the placement of adverbial elements within VP: Adverbs such as cnora 'yesterday' can intervene between a matrix verb and a clausal complement, as shown by the example in (15). If (14) were the correct structure for (13), then we would expect, all else being equal, that such an adverb could intervene between the NP object and the clausal complement. However, this is not possible. As the example in (16a) shows, enora can occur after the complement clause, but it cannot occur between no and the predicate (16b).

(15) Kofi kaa enora se Yaw be-ko Nkran.

K. said yesterday that Y. FUT-go:to Accra

'Kofi said yesterday that Yaw will go to Accra.'

(16) a. Kofi maa no kann krataa no enora.

K. made him/her read book that yesterday

'Kofi made him/her read the book yesterday.'

b. *Kofimaa no onora kann krataa no.

K. made him/her yesterday read book that

(Asante)

(Asante)

The ungrammaticality of (16b) is predicted by the analysis in which (13) has the structure shown in (14a), but is unexpected under the analysis in which it has 
the structure in (14b). Therefore, I assume that an accusative causee is an exceptionally Case-marked subject, and not a matrix object.

Second, the evidence mentioned above-that the complement of causative $m a$ is IP-covers both cases. In particular, the complement clause can be independently negated, regardless of whether the embedded subject is an SCL, as in (17a), or an accusative pronoun, as in (17b).

\section{a. Kofi ma o=n-to nwoma no. \\ K. make s/he-NEG-buy book that \\ b. Kofi ma no n-ts nwoma no. \\ K. make him/her NEG-buy book that \\ 'Kofi makes him/her not buy the book.'}

As argued in Campbell [1989] and Campbell [1995], independent negation is possible only with IP; therefore the causative-with-accusative causee cannot be analyzed as taking a bare VP complement. The examples in (17) indicate that in both the causative-with-accusative and the causative-with-SCL constructions the complement clause is IP.

Further evidence for the structural parallel between (12) and (13) comes from binding theory [Chomsky 1981]. The alternation between SCL and accusative subject in (12) and (13) is reminiscent of the alternation between nominative and accusative subjects in English, shown in (18). That (18a) and (18b) have different structures is shown by the following fact: in (18a) it is possible to construe the pronoun he as coreferential with the matrix subject $A l$, whereas the parallel interpretation, with him and $A l$ coreferential, is impossible in (18b).

\section{(18) a. Al believes (that) he is a genius. \\ b. Al believes him to be a genius.}

In the binding theory of Chomsky [1981] and subsequent work, this difference is due to there being different structural relations between the pronoun and $A l$ in the two examples. According to Condition B of binding theory, a pronominal such as he or him must not corefer with anything within the smallest clause that contains the pronoun and its governor; let us refer to this as its binding domain. In (18a), he is assigned nominative Case-and hence governed-by the finite Infl in the embedded clause, so the embedded clause itself is the binding domain for he. Since $A l$ is outside that domain, there is no violation of Condition B if he and $A l$ corefer. In (18b), him is assigned accusative Case-hence governed-by the matrix verb believe, so the matrix clause, which includes $A l$, is the binding domain for him. Therefore, a Condition B 
violation results if him and $A l$ are coreferential. The structures of (18a) and (b) are shown in (19a) and (b), respectively.

(19)

a.

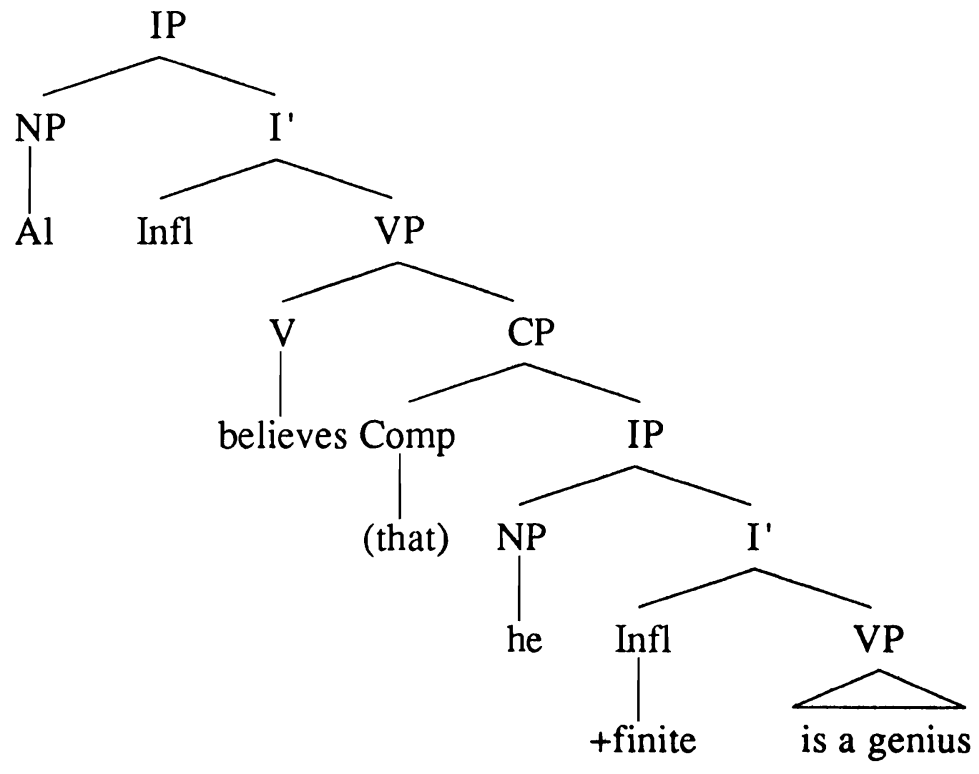

b.

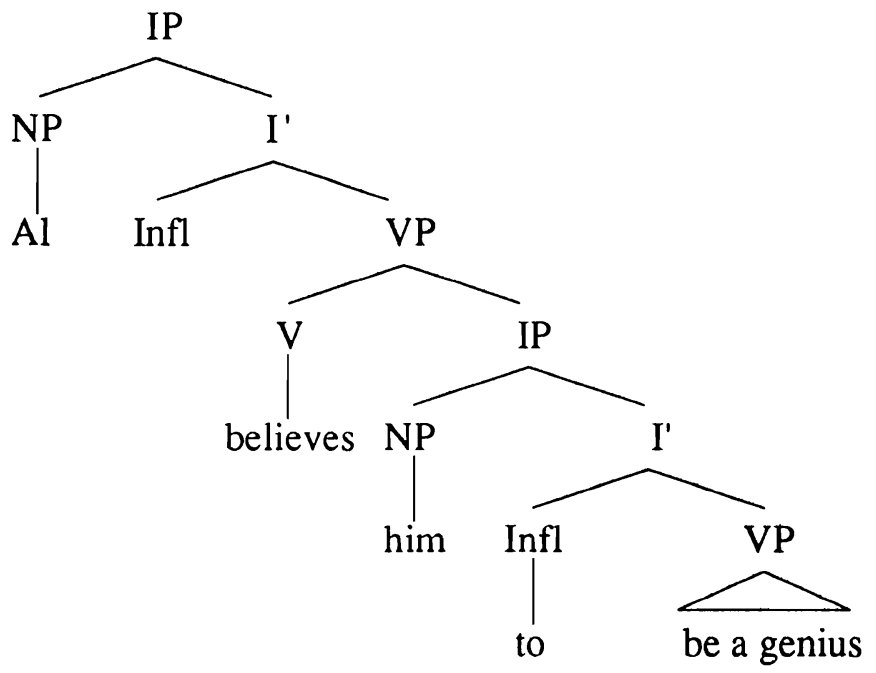

The presence of Comp in (19a) prevents the embedded subject position from being governed by the matrix verb [Chomsky 1981, 1986], so that the embedded IP itself is the binding domain for that position. Since there is no Comp in (19b), believe governs the embedded subject, so that the matrix IP is the binding domain for that position. 
Embedded full clauses in Akan have a structure very much like that of (19a); that is, with V taking a CP complement. This is shown by example (9) above, as well as by the example in (20). Like the English example in (18a), the pronominal subject of the embedded clause in (20) is free to corefer with Yaw. This shows that, as in English, the binding domain for the subject of an embedded full clause is the embedded clause, and not the matrix clause.

(20) Yaw pe se $\quad$ =n-ko Kumase.

Y. like that s/he-OPT-go K.

'Yaw wants (him/her) to go to Kumase.'

Both (12) and (13) contrast with (20) in this respect: in both examples, the pronominal causee cannot refer to Kofi. This fact follows from Condition B if we assume that the binding domain of the pronominal is the matrix clause in both cases. If the structure of both (12) and (13) is that shown in (21), then the binding domain for a pronominal causee in the embedded SpecIP is the matrix IP, which is the smallest clause containing both SpecIP and its governor, in this case V. Thus, the binding facts indicate that in both (12) and (13), V governs the causee; therefore, (12) and (13) do not differ in a manner parallel to that of (18a) and (b). Other than choice of Case on the causee, then, there does not seem to be any reason to assign them distinct structures.

$(21)$

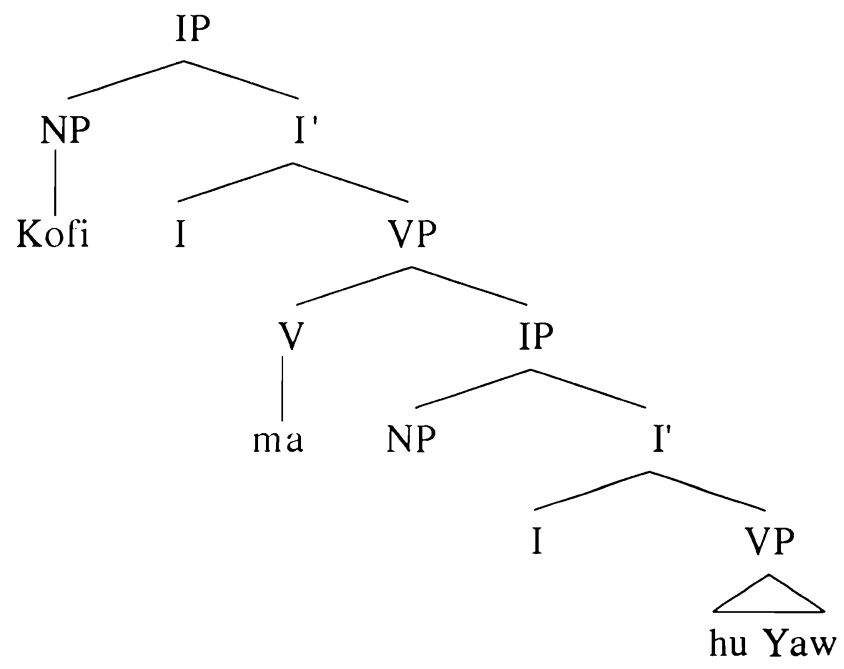

The structural parallelism between (12) and (13) is rather surprising, given the superficial similarity to the English examples in (18). Why should two different pronominal forms, semantically identical but formally distinct, be 
allowed to occur in identical environments? Accounting for this alternation is central to choosing between the argument analysis and the pro analysis: the embedded SpecIP is assigned accusative Case, by Exceptional Case Marking (ECM), in (13); in (12), either the pronoun in SpecIP is assigned nominative Case by Infl (if the argument analysis is correct), or pro in SpecIP is identified by a SCL in Infl (if the pro analysis is correct). Let us therefore examine the causee position more narrowly. In Sections 6 and 7, I will return to the issue of how to account for the alternation in (12) and (13).

\section{Object pro in causatives}

There is a surprising asymmetry in causative constructions with pronominal subjects: Although either an overt object pronoun or an SCL is possible in the embedded SpecIP position in (21) if it is [+animate], the same is not true for inanimates. A pronominal inanimate causee can be an SCL, as in (22).

a. Yaw ma $\varepsilon=k o$ ho.

Y. make it=go there

'Yaw makes it go there.'

b. Kofi ma $\varepsilon=k y c k y c r e Y a w$ bo dua no ho. $\mathrm{K}$. make it =tie up $\mathrm{Y}$. touch tree that LOC 'Kofi makes it tie Yaw up to the tree.'

c. $\varepsilon d e \varepsilon n$ na Kolï ma $\varepsilon=f i r i t o ? 7$

what FOC K. make it=fall

'What does Kofi make fall?'

Recall that the inanimate counterpart of the accusative pronoun in (13) is pro, which can occur under these circumstances without any overt identifier (see Section 3); object pro differs from overt accusative pronouns in that cannot occur in the causee position, as shown by (23). The contrast between (12) and (13) on the one hand, and (22) and (23) on the other hand, is unexpected. Since the causee position can have accusative Case, and [-animate] pro can normally appear in accusative positions, we would expect (23) to be grammatical, all else being equal.

7 In examples (22c) and (23c), the embedded SpecIP is occupied by a resumptive pronoun bound by the clefted wh-phrase $\varepsilon d e c n$ 'what'; in Kwawu, resumptive pronouns are obligatory when clefting from SpecIP [Campbell 1989]. There is no reason to believe that the nature of a SCL or of object pro is any different when it is a resumptive pronoun, rather than a nonresumptive pronoun. 


\section{a. *Yaw ma proko ho.}

$\mathrm{Y}$ make it go there

b. *Kofíma prokyekyere Yaw bo dua no ho. $\mathrm{K}$ make it tie up $\mathrm{Y}$. touch tree that LOC

c. *edeen na Kofi ma profiri to? what FOC K. make it fall

The contrast between (22) and (23) turns out to provide crucial evidence for the pro analysis of SCs: the argument analysis can account for the ungrammaticality of (23) only with additional assumptions, while the pro analysis provides a relatively more elegant explanation. In the next sections, I examine in detail how each analysis might account for this contrast.

\section{The Argument Analysis}

The statement in (24), taken as a theorem of Akan grammar, is consistent with the argument analysis of SCLs, as well as with the contrast between (23), on the one hand, and (13) and (22) on the other.

\section{(24) *pro in SpecIP}

From (24) it follows that SCLs are arguments, and also that (23) is impossible. Note, however, that (24) does not follow from any otherwise motivated assumptions about object pro in Akan. For example, if it were not for examples like (23), we could account for the fact that pro never occurs in subject position (if the argument analysis is correct) by stipulating that pro must be accusative; that will not suffice to rule out (23), however, since the causee position can be accusative.

Conceivably, (24) could follow from a more general constraint to the effect that object pro is licensed only by the verb that assigns its theta-role. Since the embedded subject in (21) gets its theta-role inside the embedded IP, pro could not be licensed in that position by the causative verb. However, this condition is probably too strong. The verb de, which occurs only as the first verb in a serial verb construction (SVC), and never in a simple sentence, is apparently a semantically empty verb that assigns no internal theta-roles [Campbell 1996]; some examples are given in (25).
a. Yaw de no
koว ho.
Y. de him/her went there
'Yaw took him/her there.' 
b. Kofi de nsuo gu fom ho.

$\mathrm{K}$. de water flow floor LOC

'Kofi pours water on the floor.'

c. Kofi de safoa bue pono no.

$\mathrm{K}$. de key open door that

'Kofi opens the door with a key.'

d. Yaw de no kyerec Koli.

$\mathrm{Y}$ de him/her showed $\mathrm{K}$.

'Yaw showed him/her to Kofi.'

e. $W o=d e$ few gyee n'asem no. they $=d e$ gladness receive his-word that 'They gladly received his word.'

[from Christaller 1875]

f. $0=d e$ dua sen agua.

$\mathrm{s} / \mathrm{he}=d e$ wood carved stool

'Of wood he carved a stool.'

[from Christaller 1875]

The NP following de can have a wide variety of roles with respect to the verb phrase, as the examples in (25) illustrate. In (25a) and (b), the NP is the subject argument of an unaccusative verb; in (25c), it is an instrumental modifying the VP; in (25d) it is the Theme argument of kyere 'show'; and in (25e) and (f), it has other, adverb-like, functions. It appears that de does not itself select the theta-role of the following NP, but merely functions to assign Case to it ((25a) and (d) show that that Case is accusative). Assuming then that de does not assign theta-roles to an object, and that the NP that follows it is, therefore, exceptionally Case-marked by de, it also follows that de can occur only in SVCs, where there is another verb to assign a theta-role to the NP Case-marked by $d e$. This is, in fact, correct, supporting the view that $d e$ is an exceptional Case-marker.

The NP that is exceptionally Case-marked by de can be pro (26), showing that object pro can be licensed in an exceptionally Case-marked position. Thus, it is not obvious that (24) can be made to follow from a more general principle, and it remains a stipulation.

(26) a. Me=de pro hohoroo me-nsa.

$\mathrm{I}=d e \quad$ it washed my-hands

'I washed my hands with it.' 
b. Yaw de pro ma no.

Y. de it give him/her

'Yaw gives it to him/her.'

c. Yaw de pro kyere Kofi.

$\mathrm{Y}$. de it show $\mathrm{K}$.

'Yaw shows it to Kofi.'

In addition to (24), the argument analysis would have to say something about the fact that (modulo (24)) the embedded SpecIP position in (21) could be assigned either nominative or accusative Case. One way to do this would be to assume that accusative can be assigned (exceptionally) to any position governed by (and adjacent to) a Case-assigning verb, and that nominative Case can be assigned to any SpecIP (presumably by Infl). Then the embedded SpecIP in (21), which meets both criteria, is free to be marked as either nominative or accusative. ${ }^{8}$ This idea is not a priori implausible, but it does not offer an explanation of the unusual fact that animate accusative pronoun and SCL can alternate freely in this position; it merely restates the phenomenon in other terms.

\section{The Pro Analysis}

The pro analysis is not consistent with the stipulation in (24) because both (22) and (23) have pro in the embedded SpecIP under this analysis. However, we can account for the contrast between these two examples by assuming that (27) holds in Akan.

(27) Pro in SpecIP is identified by a clitic in Infl.

If (27) holds, then (23) is ruled out because there is no clitic in Infl, as there is in (22). I suggest that (27) is a more plausible assumption than (24). Essentially, (27) reduces to saying that Infl must spell out the features of SpecIP, if SpecIP is pro. That Infl might record the features of SpecIP is to be expected anyway, since that is commonly assumed to be the configuration in which subject agreement applies. The stipulation in (27) should, therefore, be replaced by that in (28), which makes the relation to agreement clearer.

(28) Infl spells out and identifies (in the sense of Rizzi [1986]) the person and number features of pro in SpecIP.

The stipulation in (27) has a plausible motivation, depending as it does on the agreement relation between the head and specifier of IP; no such motivation

8 That is essentially the analysis proposed in Campbell [1989] and adopted by Campbell [1995]. 
exists for (24). Generalizing (28) somewhat, we can specify the licensing and identification of pro in Akan as in (29) and (30), respectively.

Licensing of pro:

Pro is formally licensed by V or Infl.

(30) Identification of pro:

i. Pro in SpecIP is identified by a clitic in Infl;

ii. Elsewhere, pro is [-animate].

Unlike the pro analysis, the argument analysis could account for (23) only by means of an otherwise unmotivated stipulation, namely (24). Therefore, the pro analysis must be considered superior to the argument analysis, since it provides a natural and rather elegant account of (23).

The pro analysis, augmented by (30), has another virtue. Recall that in the argument analysis, it was necessary to stipulate that the embedded SpecIP position in (21) could be assigned one of two Cases, nominative or accusative. Though this assumption is not implausible a priori, it is not strictly necessary for the pro analysis to work. Instead, we can simply assume that the embedded SpecIP always gets accusative, and that nominative cannot be assigned in ECM constructions. The reason is that (28) says nothing about pro being nominative; therefore it is possible that in (12) and (22), pro in SpecIP is assigned accusative Case, like the overt pronoun in (13). The assumption that the causee is always assigned accusative Case would bring reduced clause complements in Akan more into line with reduced clause complements in other languages, such as English, where nominative Case can be assigned only in full clauses. However, it should be pointed out that the pro analysis does not depend on this assumption; the pro analysis is consistent with the assumptions of the last paragraph of Section 6.

\section{SCLs in UG}

The evidence bearing on the choice between the argument and pro analyses is subtle, and depends entirely on negative evidence (the ungrammaticality of (23)). Therefore, it seems likely that that is not the evidence that a child acquiring Akan makes use of when she learns that her language is Pro-drop. Consequently, it is possible that it is the mere fact that subject pronouns are clitics that provides this information to the child; in other words, subject clitics always identify pro, unless there is positive evidence to the contrary.

Assuming this to be correct, what principles of UG force SCLs to be analyzed as inflectional elements, rather than as arguments; that is, what rules out the argument analysis? While I cannot provide a definitive answer, I will briefly discuss two possible explanations for this fact. The first proposal is developed from a suggestion by an anonymous reviewer: Assume that the 
sequence SCL + host must be analyzed as a syntactic constituent. From the argument analysis, it follows that the SCL would have to move from SpecIP to adjoin to Infl (assume for the time being that $\mathrm{V}$ moves into Infl). The resulting structure would then be (31).

(31)

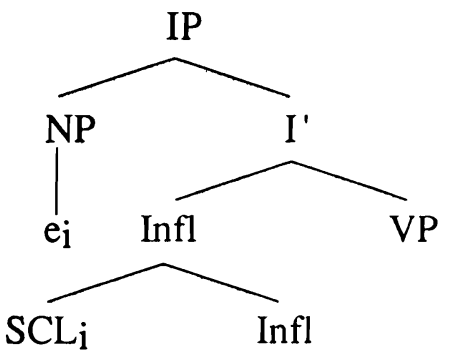

In this structure, the moved SCL does not c-command its trace, assuming a definition of c-command whereby A c-commands B only if the first category dominating A also dominates B. In (31), the first category dominating SCL is I', which does not dominate SpecIP.9 As a result, the trace in SpecIP is not antecedent governed, and the Empty Category Principle (ECP) [Chomsky 1986] is violated. Therefore, the structure in (31) is impossible according to this approach.

One consequence of this idea (or some variant of it) is that while SCLs would necessarily be analyzed as non-arguments, object clitics (OCL) could potentially be analyzed as arguments. Assuming an argument analysis of OCLs in some language, movement of the OCL to adjoin to Infl would result in a structure like (32).

(32)

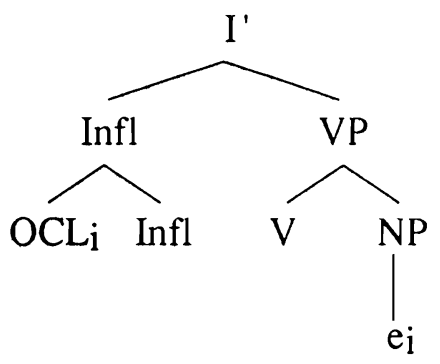

In (32), the first category dominating OCL is I' (see note 9), which also dominates the trace in object position. Therefore, no ECP violation would

9 Following the proposals in May [1985] and Chomsky [1986], I assume that both Infl nodes together constitute a single occurrence of the category Infl; since it is not the case that both nodes, or segments, of Infl dominate SCL, it is therefore not the case that the category Infl dominates SCL. 
necessarily result under an argument analysis of OCLs. A pro analysis of OCLs should also be possible, all else being equal. Therefore, the ECP-based account of the impossibility of an argument analysis of SCLs makes no strong predictions about OCLs.

An alternative explanation of the unavailability of argument SCLs is based on the notion of markedness. Suppose UG provides two options for the analysis of clitics: the unmarked option is that the clitic is a functional head (e.g., Infl), while the marked option is that the clitic is a phrase (e.g., an NP). A child learning a language with clitics will assume the unmarked option, unless there is positive evidence that the target language makes use of the marked option. There is no positive evidence in Akan that SCLs are arguments; therefore, the child learning Akan will fall back on the unmarked option, namely the pro analysis, where the SCL is a functional head. Unlike the ECP-based account, the markedness-based account predicts the same range of options for both SCLs and OCLs; namely, that they will be analyzed as functional heads, unless the language learner is exposed to positive evidence to the contrary.

Which, if either, of these proposed explanations proves correct remains to be seen. However, it seems clear that some UG-based account of the absence of the argument analysis for Akan SCLs is called for.

\section{Conclusion}

In this paper I have argued that an analysis of Akan SCLs whereby SCLs are inflectional morphemes generated in Infl (the pro analysis) is superior to one whereby SCLs are arguments (the argument analysis). Thus, Akan is a pro-drop language, allowing null pronominal subjects under certain circumstances. This conclusion rests on the fact that the pro analysis provides a natural account of the ungrammaticality of (23); essentially, pro in SpecIP must be locally identified by a clitic in Infl. The argument analysis, on the other hand, accounts for (23) only by means of an unmotivated condition on pro, which essentially stipulates that examples like (23) are ungrammatical.

\section{REFERENCES}

Campbell, Richard. 1988. "Verbal inflection in Kwawu Akan." Studies in African Linguistics 19, 205-232.

Campbell, Richard. 1989. "The Grammatical Structure of Verbal Predicates." $\mathrm{Ph} . \mathrm{D}$. dissertation, UCLA (available as UCLA Dissertations in Linguistics, vol. 13). 
Campbell, Richard. 1995. "Inflectional domains and Comp features." Lingua 96: 119-138.

Campbell, Richard. 1996. "Serial verbs and shared arguments." The Linguistic Review 13: 83-118.

Chomsky, Noam. 1981. Lectures on Government and Binding. Dordrecht and Cinnaminson, N.J.: Foris Publications.

Chomsky, Noam. 1986. Barriers. Cambridge, Mass.: MIT Press.

Christaller, J.G. 1875. A Grammar of the Asante and Fante Language Called Twi. Basel: Basel Evangelical Society.

Dolphyne, Florence A. 1988. The Akan (Twi-Fante) Language: Its sound system and tonal structure. Accra: Ghana Universities Press.

Jaeggli, Osvaldo. 1981. Topics in Romance Syntax. Dordrecht and Cinnaminson, N.J.: Foris Publications.

Kayne, Richard S. 1972. "Subject inversion in French interrogatives." In J. Casagrande and B. Saciuk (eds.), Generative Studies in Romance Languages. Rowley, Mass.: Newbury House.

Kayne, Richard S. 1975. French Syntax: The transformational cycle. Cambridge, Mass.: MIT Press.

Rizzi, Luigi. 1986. "Null objects and the theory of pro." Linguistic Inquiry 17: 501-557.

Department of Linguistics

Oakland University

Rochester, MI 48309

campbell@oakland.edu
[Received February 1998; revision received May 1998; accepted May 1998] 